\section{Cahiers d'ethnomusicologie}

Anciennement Cahiers de musiques traditionnelles

$18 \mid 2005$

\section{Entre femmes}

\title{
Ilê Omolu Oxum. Cantigas e toques para os orixás
}

(chants et rythmes pour les orishas) Edité par Edmundo Pereira et Gustavo Pacheco et réalisé par le Museu Nacional de Rio de Janeiro (Brésil). 2004

\section{François Borel}

\section{OpenEdition}

\section{Journals}

Édition électronique

URL : http://journals.openedition.org/ethnomusicologie/432

ISSN : 2235-7688

Éditeur

ADEM - Ateliers d'ethnomusicologie

Édition imprimée

Date de publication : 31 décembre 2005

Pagination : 338-339

ISSN : $1662-372 X$

Référence électronique

François Borel, "llê Omolu Oxum. Cantigas e toques para os orixás », Cahiers d'ethnomusicologie [En ligne], 18 | 2005, mis en ligne le 14 janvier 2012, consulté le 05 mai 2019. URL : http:// journals.openedition.org/ethnomusicologie/432

Ce document a été généré automatiquement le 5 mai 2019.

Tous droits réservés 


\section{Ilê Omolu Oxum. Cantigas e toques para os orixás}

(chants et rythmes pour les orishas) Edité par Edmundo Pereira et Gustavo Pacheco et réalisé par le Museu Nacional de Rio de Janeiro (Brésil). 2004

\section{François Borel}

\section{RÉFÉRENCE}

Ilê Omolu Oxum. Cantigas e toques para os orixás. (chants et rythmes pour les orishas) $1 \mathrm{CD}$ Edité par Edmundo Pereira et Gustavo Pacheco et réalisé par le Museu Nacional de Rio de Janeiro (Brésil). Brochure de 32 pages (non numérotées) avec illustrations, texte en portugais et résumé en anglais. Coleçao Documentos sonoros, 109.824 - DSMN 01 / 04 , 2004.

1 Ce disque constitue le premier de trois volumes de la "Coleção documentos sonoros ", éditée par le Musée national de Rio de Janeiro. Il est consacré aux chants sacrés des rituels du candomblé brésilien et porte le nom, Ilê Omolu Oxum, de l'un des terreiros (lieu de culte) religieux les plus traditionnels du Brésil. Celui-ci est situé à São João de Meriti, dans la banlieue nord de Rio, où il fut fondé par Mâe Meninazinha d'Oxum, prêtresse (en langue yoruba: ialorixá; en brésilien: mâe de santo) du culte, elle-même initiée au candomblé en 1960 par sa grand-mère Iyâ Davina d'Omolu, à la Casa Grande de Mesquita de Rio de Janeiro. Mais c'est déjà dans les années 1920 que s'installèrent les premiers candomblés à Rio, en provenance de Salvador de Bahia, terre d'origine des candomblés brésiliens. Il ne s'agit donc pas ici de la musique d'un culte de Umbanda, ni de celle d'une macumba, mêlant spiritisme, catholicisme et culte de divinités d'origine africaine, mais bien de celle d'un authentique culte de divinités orishas d'origine yoruba, que les Brésiliens qualifient de tradition Ketu (nação queto). 
2 C'est dans un élan commun que le Musée national, le LACED (Laboratório de pesquisas em etnicidade, cultura e desenvolvimento) et le terreiro Ilê Omolu Oxum ont décidé d'effectuer ces enregistrements. En effet, il devenait indispensable de conserver et de publier la mémoire des chants et des rythmes liés au divinités yoruba, ce patrimoine immatériel, témoin de "l'alliance humaine avec les dieux", comme l'écrit un des coordinateurs (p. 3), qui contribue à confirmer et à faire reconnaître le caractère pluriethnique de la société brésilienne, trop longtemps confinée dans l'image d'un « métissage culturel » occultant certaines formes cachées de discrimination et de racisme. Car le candomblé ne peut être réduit exclusivement à ses fonctions religieuses. Il sert aussi à organiser la vie sociale, où il joue un rôle essentiel en formant la conscience et l'identité des descendants d'Africains.

3 Les enregistrements ont été réalisés à l'aide d'un studio mobile en mars 2001 et en janvier 2004 au sein même du terreiro, dans un local acoustiquement plus approprié que le barracão où se déroulent habituellement les toques. Après plusieurs auditions réunissant les musiciens et tous les protagonistes, ils furent complétés par quelques séances partielles en studio destinées à doubler les chœurs et à corriger quelques imperfections rythmiques et mélodiques. Le mixage final permit de «trouver clareté et équilibre dans la relation entre les voix (soliste et chœur) et entre celles-ci et les tambours » (p. 24).

4 Le CD présente donc le répertoire complet des chants, des rythmes de tambours et de leurs variantes, joués lors des différentes phases d'appel aux divinités orisha durant la cérémonie, en tout 51 plages consacrées successivement aux divinités suivantes: Exu, Ogum, Oxóssi, Ossain, Omolu, Oxumaré, Nanã (Buruku), Oxum, Iansã, Iemanjá, Xangô, Obá, etc. L'excellente qualité des enregistrements, due aux moyens techniques à la disposition des enquêteurs, ne parvient cependant pas à compenser, chez les chanteurs et les musiciens, un manque de spontanéité d'autant plus évident à l'oreille que les chants et les rythmes se ressemblent beaucoup, en fin de compte. Certes, le but de ces séances était le recensement du patrimoine et non pas une tentative de restitution d'une cérémonie. Mais il est difficile d'empêcher la monotonie et l'ennui de s'installer rapidement au fil de l'écoute, tant l'impression d'enregistrement « sur commande » prédomine.

Rappelons que des documents similaires, mais beaucoup plus "authentiques » ont été recueillis par Gérard Béhague à Salvador dans les années 1970 et par Tiago de Oliveira Pinto en 1988, alors que Xavier Vatin a fait de même plus récemment dans un candomblé Angola.

6 La brochure du CD décrit surtout les circonstances qui ont présidé à la création de cette collection, ainsi que la lignée des Pères et Mères de saints qui ont engendré les candomblés de la région de Rio, et dont des photos émaillent le texte. Peu d'informations sont en revanche données sur les chants et les rythmes utilisés et leurs relations avec les divinités invoquées. Un disque qui réjouira sans doute les spécialistes du candomblé. 